\title{
La oposición antifranquista leonesa. De la posguerra a la nueva conflictividad
}

\author{
Sara González Castro \\ Becaria de Investigación. Universidad de León \\ David Martínez Pérez \\ Doctorando de la Universidad de León \\ The opposition to Franco in Leon. from the Postwar peirod \\ to the new unrest
}

\begin{abstract}
RESUMEN
El ensayo analiza las características de la oposición leonesa al franquismo. Desde el 18 de julio de 1936 los militares sublevados tenían un objetivo principal que era acabar con los disidentes de la ideología que intentaban imponer. Para conseguirlo la represión fue su principal herramienta.

Durante la década de los 50 la oposición no sufrió cambios importantes siendo más destacados en las décadas posteriores.
\end{abstract}

PALABRAS CLAVE represión, violencia, oposición, franquismo.

\section{ABSTRACT}

This essay analizes the characteristics of the opposition to Franco in Leon.

From the 18 of 1936 july the incited military had a main objetive, it was to end the ideology they tried to impose. To get it, the repression was their apliancee.

During the decade of the 50 opposition didn't have important changes being more prominent in the decades later.

KEY WORDS

repression, violence, opposition, franquismo. 


\section{EL INICIO DE LA GUERRA EN LA PROVINCIA DE LEÓN}

La tensión política y social era notable a comienzos del verano de 1936 en todo el país. Culminaría con la sublevación militar que triunfó en León capital el día 20 sin encontrar apenas oposición los militares sublevados. El levantamiento se extendió por la mayor parte de la provincia sin encontrar casi resistencia quedando ésta bajo el control de los alzados, con la excepción de la zona septentrional limítrofe con Asturias. Hay que tener en cuenta que León era una provincia tradicionalmente conservadora. Sería en esta zona norte donde se establecería la línea del frente que caería el 20 octubre de 1937. Tras este hecho un gran número de combatientes republicanos fueron hechos prisioneros corriendo diversa fortuna, desde ser aniquilados, escapar a las montañas para formar las guerrillas o ser enviados a las cárceles franquistas.

La crueldad de la represión franquista que es la sufrida mayoritariamente en nuestra provincia, fue debido como, señala Francisco Moreno a que: «Fue una represión de Estado, programada e impulsada desde arriba ${ }^{1}$.» El carácter ejemplificador del castigo no buscaba sólo penar a los transgresores sino, sobretodo, impedir una futura oposición, forzando a la pasividad, a la despolitización y a la sumisión. Una represión que se percibe como una continuación de la guerra y como el elemento clave del nuevo sistema de poder, como señala Francisco Carantoña: 'La represión del bando franquista trataba de asegurar la retaguardia por medio del terror y después se pretendió asegurar el asentamiento del régimen por el mismo sistema. Sólo el objetivo de provocar la paralización del contrario por medio del pánico puede explicar al represión franquista de guerra y postguerra ${ }^{2}$.

\section{ALGUNOS ASPECTOS DE LA REPRESIÓN}

León vivió con todo su rigor la represión de los sublevados desde el 20 de julio de 1936 y el resto de la provincia a los pocos días. Por esta razón tiene especial interés analizar las características del sistema represivo organizado por ellos.

Abordaremos esta cuestión teniendo en cuenta no sólo a las víctimas de la represión física o que sufrieron las penalidades de las prisiones, campos de concentración etc., también aquéllos que vieron el embargo de sus bienes, la pérdida de sus ingresos económicos o de sus trabajos. Como señala Carmen Molinero: «Las víctimas mortales son la cara más dramática de la represión pero no la única ni la más numerosa ${ }^{3}$ «. El miedo a que sobrevivieran elementos que pudieran ser

1 MORENO GÓMEZ, F: «El terrible secreto del franquismo», La aventura del Historia, 3, (1999), pp.12-25.

2 CARANTOÑA ÁLVAREZ, F: «La represión. San Marcos», en PUENTE FELIZ, G. y CARANTOÑA ÁLVAREZ, F.(coords): La guerra civil española en León. León, Diario de León, 1987, p.486.

${ }^{3}$ MOLINERO, C: «¿Memoria de la represión o memoria del franquismo?» en JULIÁ, S. (Dir.): Memoria de la guerra y el franquismo, Madrid, Taurus, 2006, p.222. 
un obstáculo al nuevo régimen que iba a instaurarse fue lo que les llevó a actuar de manera violenta acabando con cualquier posible persona o grupo subversivo, de ahí que se llevaran a cabo los paseos, consejos de guerra, depuraciones, incautaciones de bienes etc. No obstante, no lograrían acabar con la oposición al régimen como se demuestra con el fenómeno de las guerrillas, muy destacado en la provincia de León.

En los primeros años, especialmente 1936 y 1937, la actividad represora se centró en las ejecuciones irregulares, éstas superaron en número a las derivadas de sentencias dictadas por tribunales militares. Los montes de Villadangos, Valverde del Camino, San Isidro, el depósito de máquinas de la Azucarera, Puente Castro, Montearenas en Ponferrada, son algunos de los lugares donde se llevaban a cabo. Se conocen las cifras de paseados de León aportadas por Salas Larrazabal que las situó en 785 . Investigaciones posteriores han desvirtuado estos números. Los datos aportados posteriormente al estudio de Larrazabal corroboran su inexactitud, por ejemplo Secundino Serrano en un estudio de las víctimas de la represión utilizando como fuente el Registro del Cementerio de León da la cifra de 1018 fallecidos a causa de fusilamientos y paseos acaecidos tan sólo en la capital. Este mismo autor plantea la hipótesis de que sean cerca de 3000 las víctimas reales de la represión franquista en la provincia de León ${ }^{4}$.

Algunos datos de paseados que podemos nosotros aportar a estas cifras obtenidos en los registros civiles son: cuatro en Sancedo, seis en Cacabelos, 15 en Balboa, 23 en Vega de Valcarce, cinco en Truchas, dos en Enciendo, dos en Castrillo de Cabrera, siete en Carrocera; en el Registro de la Pola de Gordón las cifras son muchos más altas por ser ésta zona de frente, lo que además ha hecho posible que también se hayan podido contabilizar las muertes de aquellos "sacrificados por las hordas rojas» tal como se cita en los libros de registro, siendo 26 las víctimas del franquismo y 15 de los republicanos. Por fuentes orales hemos obtenido un listado de personas desaparecidas, las cifras son: 21 personas residentes en Bembibre, una en Rodanillos, dos en Losada, una en Labaniego, cuatro en San Román de Bembibre. También nos ha sido facilitada una relación de 20 personas fusiladas en Ponferrada el cinco de mayo de $1937^{5}$.

Otro aspecto de la represión fueron los consejos de guerra, aquí es donde queda patente el carácter selectivo y organizado de la represión ya que en los primeros años fue dirigida hacia autoridades políticas, militares, destacados republicanos, dirigentes políticos y sindicales. En un principio las ejecuciones se realizaban pocos días después de la celebración del juicio. En la provincia de León un interesante ejemplo de esto es que el 4 noviembre de 1936 fueron juzgados y el 21 fusilados en Puente Castro, las autoridades republicanas más importantes: el gobernador civil Emilio Francés, el presidente de la Diputación Ramiro Armesto, el

\footnotetext{
${ }^{4}$ ÁLVAREZ OBLANCA, W. y SERRANO, S: «La guerra civil en León», Tierras de León, 67, (1987),

${ }^{5}$ Estas cifras debemos tomarlas con cautela puesto que han de ser contrastadas.
} p. 86. 
Alcalde de León Miguel Castaño, el dirigente comunista José María de Celis y Antonio Fernández Martínez el líder del Sindicato Minero Castellano Leonés, entre otros. De todos ellos tenemos constancia que pasaron por la cárcel provincial de León y San Marcos. Son muy significativas a este respecto unas cartas personales escritas desde la prisión del por aquel entonces alcalde de León, Miguel Castaño, en las que se muestra claramente la desmoralización, desesperación e impotencia de la situación que ahí vivían. En la causa con Emilio francés estaban englobadas otras 30 personas, entre las que se encontraban destacados personajes de la sociedad leonesa del momento. También pasaron por situaciones similares otras autoridades como los alcaldes de Ponferrada, Juan García Arias, que también estuvo en la cárcel de León antes de su ejecución; el de Sahagún Benito Pamparacuatro, o el de Astorga Miguel Carro Verdejo, entre otros. También resultaron represaliados militares y fuerzas de orden público que permanecieron fieles a la República como el capitán Juan Rodríguez Lozano, que fue ejecutado. Los consejos de guerra se incrementaron tras la caída del Frente Norte en octubre de 1937. A partir de 1938 los juzgados eran básicamente milicianos que lucharon en el frente. Entre julio de 1936 y diciembre de 1940 unos 8000 leoneses pasaron por los juicios sumarísimos 6 . Según Salas Larrazabal serían 624 personas las fallecidas a causa sentencias judiciales en León, a todas luces resulta inexacta esta cifra.

Aquellos que se libraron de la muerte pasaron varios años en las cárceles de la provincia. La prisión más conocida es el campo de San Marcos que funcionó como tal desde julio 1936 a noviembre de 1939 y que llegó a contar en algunos casos con 7000 hombres y 300 mujeres reclusas ${ }^{7}$. Las condiciones de vida allí fueron muy duras por el frío, la humedad, el hambre, el hacinamiento, las palizas como así ha descrito Victoriano Crémer que estuvo allí recluso ${ }^{8}$.

Hemos podido ampliar la información que de otras prisiones de la provincia tenemos, así por ejemplo de la Prisión Provincial de León contamos con cerca de 5000 expedientes de presos políticos, en muchos casos leoneses que pasaron por ella desde el año 36 a principios de la década de los 50 . Aquí hemos encontrado los expedientes de algunas personas que jugaron un papel importante como elementos de oposición al franquismo en las décadas posteriores como Felipe Díez Iglesias. Las condiciones de vida en esta cárcel eran según Crémer: «Salvo casos muy especiales no se practicaba la tortura física ni la humillación alcanzaba mayor grado que el derivado de los reglamentos. El personal era severo, riguroso pero no brutal ni degenerado; la comida era mala, pero soportable en régimen de reclusión y las normas nos permitían lecturas, recreos, paseos y practicas higiénicas normales [...] estaba abarrotada de detenidos políticos y con una docena de presos comunes ${ }^{9}$ ».

6 ÁlvaREZ OBLANCA, W. y SERRANO, S: Crónica Contemporánea de León, León, La Crónica 16 de León,1991.

7 ÁLVAREZ OBLANCA, W. y SERRANO, S: «La guerra civil en León»,cit., p.85.

8 CRÉMER, V: El Libro de San Marcos, León, Lebrija, 1980.

9 CRÉMER, V: op.cit., p. 732. 
Sobre la prisión de Astorga albergó en este periodo de tiempo a más de 9000 presos políticos, cuya procedencia es mucho más variada que la de la prisión provincial. Otros centros penitenciarios destacados conocemos la situación de la cárcel de Valencia de Don Juan con 74, la de La Bañeza 290, y la de Villafranca en la que hemos contabilizado 386 presos por causas políticas todos ellos ingresados en la prisión entre los años 1936-1939, tuvo por tanto función de prisión preventiva por lo que los presos no pasaban allí largas épocas siendo trasladados a los principales centros penitenciarios de la provincia ${ }^{10}$.

Muchos milicianos también redimieron sus penas con el trabajo en destacamentos penales o batallones de trabajadores, el más importante de la provincia era el perteneciente a Minas Moro S.A situado en Fabero y que posteriormente fue trasladado a Matarrosa del Sil. Conocemos también la existencia en el Bierzo de un destacamento, el del Canal del Bajo Bierzo del que podemos aportar datos relevantes tras haber encontrado documentación inédita. Los trabajadores de este destacamento eran todos ellos presos de la Prisión del Partido de Ponferrada, por la información encontrada se sabe que trabajaron en la realización de este canal que se localiza cerca de Camponaraya durante el año 1944, siendo el número de trabajadores variable, fue el mes de septiembre en el que más hubo con un total de $88^{11}$.

Otro aspecto que se conoce sobre la represión en la provincia de León son las depuraciones siendo la más conocida la que afectó al personal educativo, por Wenceslao Álvarez Oblanca sabemos que 40 maestros fueron paseados o fusilados en la provincia, en el magisterio primario se instruyeron 905 expedientes siendo 186 separados definitivamente de su puesto. En cuanto a la enseñanza media y superior las comisiones depuradoras sancionaron al $80 \%$ de los profesionales, y un $10 \%$ fueron separados definitivamente.

Por último, debemos tratar otro tipo de represión, nos referimos a las actuaciones de las Comisiones Provinciales de Incautación de Bienes que funcionaban desde 1937 hasta 1939. La comisión Provincial de León instruyó expedientes a 3105 leoneses en estos años ${ }^{12}$. Claro está que estas sanciones eran complementarias y no excluyentes a las impuestas por otros tribunales o autoridades.

\section{LA OPOSICIÓN FRANQUISTA EN LA DÉCADA DE LOS CUARENTA: LA GUERRILLA LEONESA}

Al final de la guerra resulta difícil hablar de oposición ya que el franquismo, como hemos visto, llevó a cabo una dura represión sobre todo aquello que pudiera suponer el mínimo atisbo de contestación al nuevo orden establecido. A pesar

\footnotetext{
10 Archivo Prisión Provincial de León (A.P.P.L) Sección Guerra civil, Prisiones de Partidos judiciales.

11 A.P.P.L, Sección Guerra civil, Prisiones de Partidos judiciales.

12 Archivo Histórico Provincial (A.H.P) Audiencia Provincial de León, Tribunal de Responsabilidades Políticas.
} 
de ello no pudieron evitar el nacimiento y la consolidación de una sólida oposición armada, que destacó en la década de los cuarenta y que tiene un papel muy destacado en la provincia leonesa.

Las investigaciones de Secundino Serrano son fundamentales para conocer las características del fenómeno guerrillero en León. El grueso de los huidos leoneses se concentró en el Bierzo y la Cabrera, especialmente en las zonas limítrofes con Orense y Lugo, donde la orografía del terreno favorecía la vida clandestina. En un primer momento el objetivo de estas personas era la supervivencia frente a la durísima represión desatada. Se formaron diversos grupos entre los que destacaron guerrilleros como Manuel Álvarez Arias, Bailarín, David Fuentes Álvarez, Velasco, Manuel Girón Bazán el Girón, Marcelino de la Parra Casas, Parra, Abelardo Macías Fernández, el Liebre, Serafín Fernández Ramón, Santeiro, los hermanos Pitaciegas, Marcelino Fernández Villanueva, el Gafas.

En un principio las diversas partidas existentes por la provincia, entre las que destacaba el grupo de Casayo uno de los mas activos, tenían unas características comunes, en ellas había pluralidad política y sindical, tenían una actitud defensiva y no tenían planes de organizarse política y militarmente con el fin de hacer frente al nuevo régimen. Esto último cambiaría a partir de la primavera de 1941 cuando entre las diversas partidas llegaron a la conclusión de la conveniencia de crear una organización guerrillera, y así a principios de verano nacieron los primeros reglamentos que ponían fin a la desorganización existente hasta entonces, se creó una Dirección ambulante. Sería en la primavera de 1942 cuando se oficializó la Federación de Guerrillas de León-Galicia cuyo fin era encauzar tanto política como militarmente la lucha antifranquista aprovechando la coyuntura internacional, se eligió un comité director, presidido por Marcelino Fernández, se crearon unos estatutos y unos objetivos políticos a realizar y se crearon así las líneas maestras de la guerrilla que serían revisadas y ampliadas en sucesivas asambleas y congresos de los que llegó a haber cinco. Su organización llegó a ser tal que llegaron a editar el primer periódico de la resistencia española «El Guerrillero». Pero a partir de 1945 empezaron los problemas, los intentos de miembros del PCE de hegemonizar la guerrilla, disparidad de criterios, se perdió la esperanza se intervención extranjera en España, esto unido a una mayor acción represora franquista a todo lo relacionado con la guerrilla llevó finalmente a la disolución de la Federación y la marcha al extranjero de muchos de sus miembros. Sólo quedaría un grupo residual en la Cabrera dirigido por Girón, su muerte en el 1951 marcó el fin del ciclo guerrillero en León cuyo balance fue: 59 muertos entre la población civil (siete sacerdotes), 60 guerrilleros, 23 enlaces, 11 guardias civiles y 12 heridos, dos muertos por parte del ejército y tres de la Policía Armada ${ }^{13}$.

En las décadas de los cincuenta y sesenta se produjo un cambio en la imagen del régimen también en la oposición. Ésta se transformará en sus objetivos, porque

13 ÁlVAREZ OBLANCA, W. y SERRANO, S: «La guerra civil en León», cit., p.106. 
las soluciones de tipo violento o insurreccional son netamente minoritarias y también en su composición política, social y generacional. No sólo estará compuesta por quienes estuvieron implicados directamente en la guerra, sino que aparecen quienes no la vivieron y sectores de clases medias y de orientación política moderada que no habían estado presentes en la oposición de posguerra.

\section{LOS INTENTOS DE RECONSTRUIR LAS ESTRUCTURAS DEL PCE}

Los intentos de reconstrucción de los distintos grupos de la oposición antifranquista continuaron en León durante los años cincuenta, aunque cambiaron en su forma de actuar. De esta forma abandonaron la violencia, pasando a realizar acciones pacíficas centradas en los problemas sindicales o políticos, aunque en el caso leonés no pasasen en muchas ocasiones de la realización y distribución de octavillas. Sin embargo en el caso leonés comenzará a resultar clave el sector minero, puesto que será un ámbito donde el movimiento antifranquista calará en mayor profundidad. Será en estas zonas montañosas donde se producirá un mayor relevo generacional, de forma similar a otras zonas de España, pero a diferencia del resto de la provincia donde habrá cierto continuismo con respecto a aquellos que vivieron la Guerra Civil.

\subsection{La célula comunista de Santa Lucía de Gordón}

Víctor-Manuel Bayón García era militante del PCE desde 1951, miembro de su Comité Central desde 1965 y responsable, secretario político o instructor desde este momento de las provincias de León, Zamora, Salamanca, Valladolid, Palencia y Santander, en las que actuó bajo el seudónimo de Carlos hasta la legalización del partido. En este puesto de responsabilidad tuvo como cometido: «[...] la función de dirigir y encauzar la lucha de los sectores progresistas en busca de una estabilización democrática». Con la llegada de la Transición, en diciembre de 1976, fue secretario político del Comité Provincial de León hasta dos años después ${ }^{14}$. La llegada a León de Víctor Bayón, que se produjo en mayo de 1965, fue en calidad de responsable o secretario político, aunque el término interno con el que era conocido fue el de instructor ${ }^{15}$.

Pese a ser asturiano, anteriormente había tenido contacto con la provincia de León cuando vino a trabajar a Santa Lucía de Gordón. Como explica él mismo:

14 Certificado expedido por el Comité Provincial de León del PCE el 12 de junio de 1979 perteneciente al archivo de Víctor-Manuel Bayón García.

15 ÁLVAREZ VEGA, H., SARMIENTO GARCÍA, T., y MARTÍNEZ PÉREZ, D: El desarrollo de la oposición política a través de la problemática laboral leonesa: 1962-1975. León, Universidad de León, 2006, p. 36. 
«Yo ingreso en el Partido Comunista en el [19]51, me afilio al Partido Comunista en la clandestinidad, en el [19]52 nos va a buscar de Santa Lucía la empresa Vasco Leonesa para una explotación de carpa vertical y en el año [19]53 organizamos una célula del Partido Comunista en Santa Lucía. Como los compromisos que la empresa había tenido con nosotros como mineros asturianos no se cumplieron volvimos otra vez para Asturias ${ }^{16} . »$

Probablemente la conflictividad laboral resurgió en escasa medida, entre los mineros leoneses, durante 1958. En marzo había comenzado una huelga en Asturias que debido al contacto de ambas zonas mineras tal vez llegase a la provincia leonesa, pero las referencias al respecto son escasas ${ }^{17}$.

\subsection{La desarticulación del PCE leonés tras el VI Congreso del PCE}

En enero de 1960 tuvo lugar el VI Congreso del PCE en Praga ${ }^{18}$. Posteriormente se produjo una importante caída de la organización del PCE en toda España, inclusive en León, puesto que cuando volvieron los participantes, muchos fueron detenidos. Las actuaciones judiciales no se hicieron esperar como muestra este extracto:

\section{«TRIBUNAL MILITAR EVENTUAL DE LEÓN}

Causa Sumarísima número 47 - 1960 por Rebelión Militar.

RESULTANDO PRIMERO: que en León [...] hasta los primeros días de febrero del año en curso en que son descubiertos por la Policía venían desarrollándose actividades encaminadas a la constitución de una organización clandestina del partido comunista $[\ldots]$

Tales contactos tienen lugar en un bar llamado el bar Secre en el cual, y aun en el local abierto al público, se prodigan las conversaciones contra el régimen político actual dirigidas hábilmente [sic] por el propietario Ángel Rodríguez Valle que es el principal responsable del partido en la Ciudad de León, asistente al VI congreso Comunista español celebrado en Praga (Checoslovaquia) y procesado en la causa General que se sigue en la I Región Militar [...] las directrices fundamentales de la misma serían [...] hacer labor de captación [...] difusión de la propaganda... reparto de octavillas incitando a la huelga [...] desenvolvimiento de toda esta actividad de forma pacífica, cuyo fruto sería la huelga general y sus últimas consecuencias el derrocamiento de la situación actual y la caída del régimen.

La intervención de los procesados fue muy diferente en el obrar en ese cuadro general de actividades [...] Julián Barrera Álvarez, militante de FET y de la JONS en la guerra de liberación [...] frecuentaba el bar Secre [...] allí escuchaba conversa-

16 Entrevista a Víctor-Manuel Bayón García: 20 de marzo del 2003.

17 ÁLVAREZ FERNÁNDEZ, F. «La oposición a la dictadura», en CARANTOÑA ÁLVAREZ, F. (coord.): Historia de León. Edad Contemporánea. Vol. IV. León, Universidad de León, 2000, p. 455. CORDERO DEL CAMPILLO, M. «La dictadura franquista en León, 1950-1973» en ÁLVAREZ OBLANCA, W. y SERRANO, S: Crónica Contemporánea de León. León, La Crónica 16 de León, 1991, pp. 329-331.

18 FERNÁNDEZ VARGAS, V: La resistencia interior en la España de Franco. Madrid, Ediciones Istmo, 1981. 
ciones [...] era considerado (por el dueño del bar) persona en la cual se podía confiar. José María Arias Cachero Valbuena, condenado por sentencia de 15 de Junio de 1938 a la pena de muerte, conmutada posteriormente por la de 20 años por Rebelión Militar [...] en los meses de abril y mayo de 1959 es abordado por un enlace del partido comunista, para él desconocido, invotándole a asumarse [sic] a una organización que tenía por fin derrocar la situación actual, suguiriéndole [sic] que visitara el bar Secre, Allaa [sic] acudió días mas tarde entrando en relación con el dueño del establecimiento.

Manuel Llamazares Aller, sin antecedentes penales [...] frecuentaba el establecimiento de Ángel Rodríguez con el cual cambiava (sic) impresiones [...] En Julio de 1959 recibe un paquete de doscientas o 300 octavillas incitadoras a la huelga que esparce por los barrios extremos de León (Bventas [sic] y Carretera de Asturias). Lucinio García Fernández, condenado en sentencia de 23 de Mayo de 1938 por Rebelión Militar a la pena de 20 años de prisión... era tenido por Ángel Rodríguez por persona indeseable por ser muy hablador y no apto para las actividades que su establecimiento se desarrollaban. Danuel [sic] García Fernández, condenado a la pena de 30 años de reclusión mayor en sentencia de 23 de Agosto de 1940 por Rebelión Militar [...] después de extinguir condena y encontrándose ya trabajando mantiene relación con un compañero de ideología comunista [...][que] le propone en el Año de 1957 que fuera enlace de la organización de León a lo que accedió, haviendo [sic] de ser su función el de hacer llegar los enlaces[...] Su domicilio lo tiene en Bembibre y desde allí se desplaza a León con el pretesto [sic] de ir al fucbol [sic] para ocultar su verdadero fin. En abril de 1958 [...] [se le acerca] un enlace venido de Francia recibiendo del mismo un paquete conteniendo ejemplares del mundo obrero [...] a finales otro enlace extranjero le entregó un paquete de octavillas subversivas para que él las desiminara [sic] [...] en Junio de 1959 otro enlace le encarga sembrar octavillas incitadoras a una huelga pacífica[...] en Julio de 1959 es invitado por otro enlace a quien informa que no progresan estas actividades extremistas. Se caracteriza este procesado por ser la figura entusiasta de la organización.

FALLAMOS: Que debemos condenar y condenamos a los procesados José María Arias Cachero Valbuena a la pena de UN AÑO DE PRISIÓN, Manuel Llamazares Aller a la pena de TRES AÑOS DE PRISIÓN y Daniel García Fernández a la pena de SEIS AÑOS DE PRISIÓN... y asimismo debemos absolver y absolvemos a Julián Barrera Álvarez y Lucindo García Fernández ${ }^{19}$.»

Lucinio García Fernández había sido detenido anteriormente durante unos meses en 1942 y 1949. Por lo que se encontraba entre las personas que continuaban sufriendo la represión ${ }^{20}$. No en vano este documento muestra el control que se tenía de los movimientos de la oposición, por lo que las actividades que podían realizar apenas pasaban del reparto de octavillas y de las conversaciones en un bar. Esto muestra que continuaban siendo protagonistas de la disidencia, quienes habían pertenecido al ejército republicano o habían sido juzgados y, en su caso, condenados tras la guerra.

19 Este texto fue publicado en la revista Resistencia, 4, 2006.

20 A.P.P.L., Sección Guerra civil, Prisiones de Partidos judiciales. 


\section{3. ¿La infiltración en el sindicato vertical?}

La táctica comunista de infiltración en el Sindicato vertical, que consistía en utilizar las plataformas legales para su destrucción, fue decidida por el PCE en 1948. Su llegada a León es discutible, pues comenzaron a incorporarse trabajadores, que antes de la Guerra Civil estuvieron vinculados a los partidos de izquierda, a las estructuras del sindicalismo oficial. Como muestra un informe reservado en el que se da cuenta de los asistentes a unos cursillos de Enlaces Sindicales organizados por el Departamento de Formación Sindical en la Delegación Sindical de Santa Lucía. En este documento se da cuenta del:

«[...] historial de alguno de ellos que figura en los archivos de la 108 Comandancia de la Guardia Civil:

CIRIACO CASADO HERRERO. Izquierdista y ratero. De mala conducta en general. Antes del G.M.N. estaba afiliado a los partidos de izquierdas, tomando parte en manifestaciones y huelgas, siendo uno de los que se destacaban. Iniciado el alzamiento fue detenido y en Consejo de Guerra condenado a 30 años, también fue detenido por ratero.

ELADIO SIARA HERRERO. Izquierdista y agresor. Actualmente observa buena conducta. Sin embargo en el pueblo de su naturaleza la observó mala en general, llegando incluso a agredir al alcalde de la localidad. Antes del Glorioso Movimiento era izquierdista sin que fuese sancionado. Un hermano del mismo era bastante significado de izquierdas.

NICOLÁS DE PRADO CORREA [en otra parte del documento aparece CORREAS]. Observa deficiente conducta. En el año 1934 fue uno de los principales revolucionarios en Turón, interviniendo en el asesinato de un ingeniero y de varios Padres Pasionistas. Durante el Alzamiento estuvo detenido por sus ideas extremistas y salió en libertad condicional el año 1946.

ANTONIO OCHOA PELÁEZ. Observa buena conducta. Antes del G.M.N. era izquierdista. Voluntario en el ejército rojo; se ignora si fue detenido o sancionado.

JESÚS MORENO MORENO. Observa deficiente conducta. Antes del G.M.N. era comunista. Voluntario en el ejército rojo (Columna Mangada) creyéndosele culpable del asesinato de un vecino de su localidad. Perteneciendo a citada columna se pasó a Zona nacional por la parte de Ávila para adquirir noticias del movimiento de las tropas Nacionales. Muy destacado en el ejército rojo. Al finalizar la campaña fue ingresado en prisión ignorándose la condena impuesta.

FELIPE DÍEZ IGLESIAS. Izquierdista. Observa buena conducta. Antes del G.M.N. se hallaba afiliado a la UGT. Se pasó a la zona roja voluntario en el ejército de la misma, al derrumbamiento del frente Norte fue detenido y en Consejo de Guerra condenado a la pena de ocho años ${ }^{21} . »$

21 Archivo Histórico Provincial de León. Fondo Sindicatos. Delegación. Legajo 6. VICESECRETARIO PROVINCIAL DE ORDENACIÓN SOCIAL, «Informe reservado sobre unos cursillos de Enlaces Sindicales organizados por el Departamento de Formación Sindical en la Delegación Sindical de Santa Lucía», febrero de 1960 . 
El importante número de enlaces con antecedentes de izquierdas, podría deberse a la táctica de infiltración en el Sindicato Vertical. Aunque tampoco existen más datos que apoyen esta hipótesis. Pero lo que sorprende es que se les permitiera el presentarse a las elecciones debido a sus antecedentes.

Jesús Moreno había estado condenado a 30 años por auxilio a la rebelión. Incluso había sido detenido en julio de 1959 por «actividades clandestinas de comunista», obteniendo la libertad en agosto de 1959. Felipe Díez Iglesias fue trasladado desde la Prisión Central de Gijón a León en 1940. Asimismo fue juzgado por auxilio a la rebelión y condenado a ocho años de prisión. Sería puesto en libertad en agosto de 1941. Finalmente en 1946 le sería concedido el indulto ${ }^{22}$.

\section{OTROS GRUPOS DE LA OPOSICIÓN}

Hubo algún intento de reorganizar las fuerzas opositoras moderadas, que no llegaron a ser reales. De esta forma entre 1951 y 1952 se trató de reconstruir la Federación Nacional de Mineros — vinculada a la UGT_ con los de León, Palencia, Burgos y Vizcaya ${ }^{23}$.

En 1945 se produjo la caída de la regional de la CNT en la que se encontraba englobada la provincia de León, junto con Asturias, Santander y Palencia. Tuvo lugar mediante una delación, de la misma forma que en el ámbito nacional. Así fueron detenidos Jacinto Rueda, Luis Avelino Blanco García, Juan Carballo y Juan Farago. Posteriormente se produjeron más detenciones ${ }^{24}$.

Durante estos años se debe insistir, pese a ser algo conocido, en que conflictividad laboral que tuvo lugar fue principalmente individual a través de las magistraturas de trabajo. En el caso leonés se puede defender que la práctica ausencia de conflictos colectivos, no se debió a un apoyo general a las instituciones franquistas, sino a la enorme represión de los partidos políticos y grupos sindicales anteriormente explicada y a los amplios mecanismos de coacción social del Estado 25 .

22 A.P.P.L., Sección Guerra civil, Prisiones de Partidos judiciales.

23 RODRÍGUEZ GONZÁLEZ, J: «El movimiento obrero en Castilla y León. Los mineros leoneses en 1962", en VEGA GARCÍA, R. (Coordinador): El camino que marcaba Asturias. Las huelgas de 1962 en España y su repercusión internacional. Oviedo, Ediciones Trea, 2002, p. 250.

24 ÁLVAREZ OBLANCA, W. y JUÁREZ PÉREZ, P: «La CNT leonesa en la clandestinidad: La gran redada de 1945», Tierras de León, n. ${ }^{\circ}$ 79-80, 1990, pp.3-15.

25 NICOLÁS, E: La libertad encadenada. España en la dictadura franquista: 1939-1975. Madrid, Alianza Editorial, 2005, p. 246. 


\section{LA PROBLEMÁTICA INDUSTRIAL CAUSADA POR EL PLAN DE ESTABILIZACIÓN.}

\subsection{El Plan de Estabilización}

Para liberalizar el mercado de trabajo se promulgó la Ley de Convenios Colectivos en abril de 1958 que reestructuró el marco de la negociación salarial y dio un mayor protagonismo a la Organización Sindical en la discusión de los convenios colectivos. Las medidas aprobadas por decreto-ley entre julio y agosto de 1959 aparte de la estabilización pretendían realizar una importante liberalización. De las medidas estabilizadoras destacaron los aumentos de algunos impuestos, el control del gasto público y el dar flexibilidad a los tipos de descuento e interés del Banco de España.

Como liberalizadoras destacaron las relativas al comercio exterior y la modificación de la legislación sobre inversiones extranjeras en España. Así el capital extranjero pudo participar hasta el $50 \%$ del capital de cualquier sociedad pudiendo llegar incluso a la totalidad. Esto favoreció a actividades industriales como la siderurgia, la química o la electrónica. Se procedió a flexibilizar el mercado interior, con la liberalización de precios y la disminución de controles que obstaculizaban los aumentos de productividad. El Gobierno recomendó que los futuros aumentos de salarios se vinculasen a incrementos de productividad para que así no provocasen efectos inflacionistas. El crecimiento del paro fue importante y solucionado, en gran parte, mediante la emigración hacia la Europa desarrollada ${ }^{26}$.

\subsection{La minería leonesa en el período entre 1951 y 1962}

Entre 1940 y 1958 se produjo un destacado incremento del número de trabajadores, pues el censo laboral creció un $111,6 \%$. Esto no implicó un desarrollo industrial, sino un aumento del factor trabajo, pero no de la productividad, es decir, la utilización de un mayor número de trabajadores, por ser más baratos sus salarios, que la utilización de maquinaria industrial. Por lo tanto el aumento de las toneladas extraídas se debió al mayor número de obreros. Asimismo en el sector minero volvieron a aparecer empresas con escasos recursos, al igual que en el período entre 1914 y 1918, con la idea de beneficiarse de concesiones de bajo rendimiento con pequeños desembolsos y con sistemas de explotación anticuados, basados en la utilización de una enorme cantidad de mano de obra ${ }^{27}$.

A partir de 1959 a los efectos del Plan de Estabilización se unió una crisis de consumo — debido al incremento de importaciones de combustibles líquidos- y un

${ }^{26}$ Ibidem y DI FEBO, G. y JULIÁ, S: El franquismo. Barcelona, Ediciones Paidós Ibérica, 2005.

27 FERNÁNDEZ FERNÁNDEZ, P. V: El franquismo en la provincia de León: Sus sindicatos verticales (1938-1977). León, Instituto Leonés de Cultura, 2003, p. 214. 
encarecimiento de los transportes. Esto provocó «una contracción del mercado, lo que originó un cierre de explotaciones, un descenso de la producción y suspensiones de empleo ${ }^{28}$." De esta forma las dificultades de la economía leonesa fueron importantes, como incluso percibieron los miembros del sindicalismo oficial. Ya en septiembre de 1959 el Delegado Provincial de Sindicatos, Amando Fernández redactó un informe sobre el «Ambiente económico social» verdaderamente esclarecedor. En este documento se describe la situación de la industria de forma pormenorizada:

«Aspecto general:

Reducción de las actividades empresariales al mínimo, en espera de un conocimiento claro del plan de estabilización y desarrollo real del mismo.

Minas: Reducción de un $40 \%$ de la producción, lo que trae consigo una reducción de los salarios de los productores que trabajan a destajo, aún cuando no se reduzcan las primas.»

Para la Organización Sindical los problemas más urgentes eran:

«Obreros, mineros:

Descontento general porque empieza a correrse el rumor de que se ha dejado sin efecto la esperada modificación de la Reglamentación nacional de Trabajo de minas de carbón, que al parecer estaba acordada y aprobada.

Minas antracita:

Preocupación y retención consiguiente en la marcha de las explotaciones, ante el temor de una posible liberalización de las antracitas que, de llevarse a cabo, originaría un paro total en esta rama de laboreo.»

Con respecto a lo que llamaban «ambiente psicológico»:

\section{«Empresas}

Expectación cada vez más desesperanzada ante la puesta en marcha del plan de estabilización. De él no ven más que subidas en los servicios y monopolios estatales o paraestatales, con la posible repercusión en todos los ámbitos de la vida nacional. Acostumbradas gran número de ellas, a trabajar a base de créditos bancarios, no quieren o no saben hacerlo al restringirse éstos. Desilusión ante la relación de organismos intervencionistas suprimidos, por la poca importancia de los mismos.

\section{Obreros}

Dudan de los resultados de la estabilización, ya que de momento, solo entrevén elevaciones de precios en artículos de primera necesidad, posibles reducciones en horas extraordinarias y paralización o reducción de trabajos y se temen hasta la posibilidad de llegar al despido libre.

${ }^{28}$ RODRíGUEZ GONZÁLEZ, J: Op. Cit., p. 238. 
En general ambos sectores de la producción pasan por un momento de desorientación, solicitando de la Organización aclaraciones a las múltiples dudas que se les plantean, las que no podemos facilitarles por carecer de consignas y orientaciones en este sentido.»

En este informe se profundiza en los temores que generó el Plan:

«En nuestras reuniones entre el desconcierto de unos y el temor de otros, no llegamos a nada positivo, sino que solemos quedar sumidos en mayor oscuridad y desconcierto por falta de algunas normas o ideas que sirvan para fijar posiciones.

Por todo ello, consideramos no sólo del máximo interés, sino de urgente necesidad el que se nos proporcionen orientaciones claves, sobre la marcha de la estabilización, al menos referidas a los sectores de mayor importancia económico-social en nuestra provincia, lo que es el caso de la minería del carbón y especialmente del ramo de las antracitas.

Podéis figuraros la serie de versiones y suposiciones que andan de boca en boca. Incluso se habla de que en fecha próxima se aplicará una total liberalización, lo que traería sobre la actual limitación de primas y horas extras una paralización seria de nuestras actividades mineras, habida cuenta del estado de mecanización de nuestras explotaciones y el costo de los arranques ${ }^{29}$.»

Se percibe así la desorientación que provocó el Plan de Estabilización. Los peores presagios se confirmaron en el año siguiente como muestra un escrito remitido por Jaime Torres Mosquera, que era el Vicesecretario Provincial de Ordenación Social, a la Vicesecretaría Nacional de Ordenación Social:

«Las progresivas alteraciones que en el orden laboral, se han venido produciendo en nuestra provincia los últimos meses, y más concretamente, y con mayor intensidad el pasado 15 de diciembre hasta esta fecha, nos obligan a transmitir a tu Superior Jerarquía un informe, lo más exhaustivo posible, de las anormalidades producidas, por creer que interesan a esa Vicesecretaría Nacional.»

Entre estas anormalidades en lo que respecta a las solicitudes de crisis laborales fueron presentadas tanto de despido como de cierre, principalmente de empresas mineras. Éstas se encontraban situadas en zonas con carbón de escasa calidad como: Santa María de Ordás. También en Riaño de Mercurio. Incluso en León desapareció una empresa de fabricación de cestas de mimbre. Aparte se produjeron numerosos despidos en minas de carbón, destacando en las empresas: Antracitas de Fabero o Minex. Se redujeron las tarifas de destajo en: Combustibles de Fabero, Rafael Alba, Hullera Vasco Leonesa o Hulleras de Sabero. Sobre esta situación se hace una interesante reflexión:

«Se va generalizando de manera alarmante la actitud de las empresas, encaminadas a reducir las pólizas de destajos, nos creemos en la obligación de poner-

29 A.H.P.L. Fondo Sindicatos. Delegación. Legajo 6. FERNÁNDEZ, A: «Informe sobre Ambiente Económico Social de Amando Fernández», septiembre de 1959; 
los en conocimiento a V. E, puesto que de esta especial situación se está derivando la intranquilidad social, el descontento y el escepticismo de nuestros trabajadores en la protección de la Legislación Social del Movimiento pretende otorgar ${ }^{30}$.»

Esta problemática económica y la actuación por parte de algunas empresas, unido a las deficientes condiciones de vida y trabajo de los obreros contribuyeron a la extensión y el crecimiento del malestar laboral. La percepción por los trabajadores de la situación la explica Víctor Bayón:

La problemática socio-laboral se agravará en 1961:

«En la reunión de la Sección Social del Sindicato de Combustible de Villablino de día 5 de junio del presente año, tomaron los acuerdos de interesar actuara [sic] el Organismo competente para obligar a que en las explotaciones mineras de La Mora, se figurase en los libramientos de los productores que trabajan por el sistema de destajos, todos aquellos conceptos por los que percibían remuneración, bien la base estuviera en metros, vagones, cuadros, etc. También se interesaba la correspondiente comprobación de las producciones de cada empresa por no estar de acuerdo los trabajadores con lo figurado en los correspondientes pagos [...] Estos hechos habían sido puestos directamente en conocimiento del Sindicato Nacional del Combustible y de la Vicesecretaría Nacional de Ordenación Social, alegando que ello estaba originando gran descontento entre los productores de la zona ${ }^{31}$.»

\section{CONCLUSIONES}

Las dificultades con que se encontraron los opositores durante el período que va desde 1951 a 1962 fueron múltiples. Por un lado las organizaciones sindicales y partidos políticos provenientes de la Segunda República se encontraban prácticamente desaparecidas como se ha explicado anteriormente. No en vano, sólo el PCE logrará mantener ciertos grupos de militantes, que la mayor parte del tiempo estuvieron desconectados de la dirección del exilio. La represión estatal sobre cualquier organización opositora continuará, aunque de una forma menos cruenta, pero sí contundente.

La conflictividad laboral se producirá de una forma individual, encauzada por las Magistraturas de Trabajo y la Organización Sindical. Los organismos opositores comprenderán en este momento el enorme potencial de las deficientes condiciones de vida y trabajo de trabajadores como los mineros, que posteriormente serán tan importantes en la conflictividad. El enorme temor a una represión tan acentuada, ante cualquier problema laboral hizo que no se superase un estadio de redacción de peticiones y de planteamiento de cuestiones ante el Sindicato Vertical. Las instituciones comenzaron a percibir la extensión de malestar entre los trabajadores

30 AHPL. Fondo Sindicatos. Delegación. Legajo 6. Vicesecretario Provincial de Ordenación Social, «Informe a la Vicesecretaría Nacional sobre alteraciones laborales en la provincia», 26 de enero de 1960;

31 A.H.P.L., Fondo Sindicatos. Delegación. Legajo 6. «Notas», diciembre de 1961. 
debido a la problemática generada por el Plan de Estabilización. Hasta ese momento las industrias habían aumentado sus beneficios debido a la ausencia de competencia, la protección estatal y la abundancia de obreros con escasos salarios.

Como hemos visto la renovación generacional que impulsará la oleada de huelgas de 1962 todavía no se había producido entre los opositores leoneses, de esta forma un importante número de los controlados por la instituciones represoras habían tenido cierta significación durante la Guerra Civil. A la sustitución de unos opositores por otros contribuyeron de una forma decisiva las consecuencias del Plan de Estabilización, que pasaban por la disminución de salarios, el paro o la emigración. Éstas contribuirán al incremento del malestar existente, que será convenientemente canalizado en la etapa posterior.

\section{BIBLIOGRAFÍA}

ÁLVAREZ FERNÁNDEZ, F.: «La oposición a la dictadura», en CARANTOÑA

ÁLVAREZ, F. (coord.): Historia de León. Edad Contemporánea. Vol. IV. León, Universidad de León, 2000.

ÁLVAREZ OBLANCA, W. y JUÁREZ PÉREZ, P.: «La CNT leonesa en la clandestinidad: La gran redada de 1945», Tierras de León, n. ${ }^{\circ} 79-80,1990$.

ÁLVAREZ OBLANCA, W. y SERRANO, S.: «La guerra civil en León», Tierras de León, 67, (1987).

ÁLVAREZ OBLANCA, W. y SERRANO, S.: Crónica Contemporánea de León, León, La Crónica 16 de León,1991.

ÁLVAREZ VEGA, H., SARMIENTO GARCÍA, T., y MARTÍNEZ PÉREZ, D.: El desarrollo de la oposición política a través de la problemática laboral leonesa: 1962-1975. León, Universidad de León, 2006.

CARANTOÑA ÁLVAREZ, F.: «La represión. San Marcos», en PUENTE FELIZ, G. y CARANTOÑA ÁLVAREZ, F.(coords): La guerra civil española en León. León, Diario de León, 1987.

CORDERO DEL CAMPILLO, M.: «La dictadura franquista en León, 1950-1973» en ÁLVAREZ OBLANCA, W. y SERRANO, S.: Crónica Contemporánea de León. León, La Crónica 16 de León, 1991.

CRÉMER, V.: El Libro de San Marcos, León, Lebrija, 1980.

FERNÁNDEZ FERNÁNDEZ, P. V.: El franquismo en la provincia de León: Sus sindicatos verticales (1938-1977). León, Instituto Leonés de Cultura, 2003.

FERNÁNDEZ VARGAS, V.: La resistencia interior en la España de Franco. Madrid, Ediciones Istmo, 1981.

Ibidem y DI FEBO, G. y JULIÁ, S.: El franquismo. Barcelona, Ediciones Paidós Ibérica, 2005.

MOLINERO, C.: «¿Memoria de la represión o memoria del franquismo?» en JULIÁ, S. (Dir.): Memoria de la guerra y el franquismo, Madrid, Taurus, 2006.

MORENO GÓMEZ, F.: «El terrible secreto del franquismo», La aventura del Historia, 3, (1999).

NICOLÁS, E.: La libertad encadenada. España en la dictadura franquista: 1939-1975. Madrid, Alianza Editorial, 2005.

RODRÍGUEZ GONZÁLEZ, J.: «El movimiento obrero en Castilla y León. Los mineros leoneses en 1962», en VEGA GARCÍA, R. (Coordinador): El camino que marcaba Asturias. Las huelgas de 1962 en España y su repercusión internacional. Oviedo, Ediciones Trea, 2002. 